\title{
SOME IMPROVED INEQUALITIES IN AN INNER PRODUCT SPACE
}

\section{NiCUŞOR Minculete AND RADU PĂLTĂNEA}

Abstract. The aim of the paper is to present some improvements of an extended Cauchy-Schwarz inequality for four vectors in a real inner product space and derive certain consequences.

Mathematics subject classification (2010): 46C05, 26D15, 26D10.

Keywords and phrases: Inner product space, Cauchy-Schwarz inequality.

\section{REFERENCES}

[1] J. M. AldaZ, Strengthened Cauchy-Schwarz and Hölder inequalities, J. Inequal. Pure Appl. Math. 10, 4, (2009), $116 \mathrm{pp}$.

[2] D. CHOI, A generalization of the Cauchy-Schwarz inequality, J. Math. Inequal. 10, 4 (2016), 10091012.

[3] J. A. Clarkson, Uniformly convex spaces, Trans. Amer. Math. Soc. 40, 3 (1936), 396-414.

[4] S.S. Dragomir, Some Grüss type inequalities in inner product spaces, J. Inequal. Pure Appl. Math. 4, 2 (2003), 42 pp.

[5] N. HARVEY, A generalization of the Cauchy-Schwarz inequality involving four vectors, J. Math. Inequal. 9, 2 (2015), 489-491.

[6] A. I. KeChriniotis AND K .K. Delibasis, On generalization of Grüss inequality in inner product spaces and applications, J. Inequal. Appl. 2010, 1 (2010), ID 167091. 